\title{
Direct Precipitation Method of Nano-CuO
}

\author{
Mingyu Li, Kefu Ding, Zhihao Li, Zeng Qingxuan \\ ${ }^{I}$ State Key Laboratory of Explosion Science and Technology, Beijing Institute of Technology, \\ Beijing 100081, P. R. China \\ *Corresponding author: Li Mingyu. E-mail: mingyuli@163.com
}

\begin{abstract}
Different reaction conditions were studied through orthogonal experiment and single factor experiment. Using $\mathrm{Cu}(\mathrm{NO} 3) 2$ as the reactant, water-alcohol solution $(\mathrm{H} 2 \mathrm{O}: \mathrm{CH} 2 \mathrm{CH} 3 \mathrm{OH}$ was $3: 1)$ as solvent at $20^{\circ} \mathrm{C}$ and reaction for $45 \mathrm{~min}$ could get nano-CuO with good dispersion and uniform size. Different kinds of characterization method were used to characterize the resultant. The average diameter of nano- $\mathrm{CuO}$ was $20.38 \mathrm{~nm}$ after calculated using some relevant formula, the surface area was about $21.988 \mathrm{~m} 2 / \mathrm{g}$, the pore diameter was about $3.079 \mathrm{~nm}$ and the pore volume was $1.349 \times 10-1 \mathrm{cc} / \mathrm{g}$. So the method is a feasible, low cost way to industry..
\end{abstract}

\section{Introduction}

With small structure units, high specific surface area and unique mechanical, optical, magnetic properties, nanocrystalline materials have become a focus of common attention in the 21st century [1-4]. Among nano materials, nano-CuO has played an important role in catalytic technology, bio-medicine technique, fine chemical industry and other fields and it is likely to have a good future $[5,6]$. However, bulk particle is easy to form during the preparation and application losing characteristics of nano materials $[7,8]$, so the preparation process is very essential. Commonly, solid state reaction method, hydrothermal method, alcohol-thermal method, precipitation method are the methods used in industry and laboratory, recently other methods [9-12] are found such as micro-emulsion method and laser heating gas-evaporation method. Compared with other methods, direct precipitation method has the advantages of simple preparation and low cost, so it can be widely used in industrial production [11].

In the work, different kinds of reactants, temperature, reaction time and ratio of water's volume $\left(\mathrm{V}_{\text {water }}\right)$ and alcohols' volume $\left(\mathrm{V}_{\mathrm{R}-\mathrm{OH}}\right)$ were studied through orthogonal experiment and single factor experiment, then the nano-CuO generated was characterized using X-ray diffraction (XRD), fourier transform infrared (FTIR), thermogravimetric analysis (TG), scanning electron microscopy (SEM) and particle surface area measurements to find the best preparation condition. What's more, the diameter, surface area, pore diameter and the pore volume of the $\mathrm{CuO}$ generated under best condition were measured and calculated.

\section{Experiment}

\subsection{Materials}

Materials included $\mathrm{CuSO}_{4} \cdot 5 \mathrm{H}_{2} \mathrm{O}, \mathrm{C}_{2} \mathrm{H}_{5} \mathrm{OH}$ produced by Beijing chemical plants; $\mathrm{CuCl}_{2} \cdot 2 \mathrm{H}_{2} \mathrm{O}, \mathrm{Cu}\left(\mathrm{NO}_{3}\right)_{2} \cdot 3 \mathrm{H}_{2} \mathrm{O}$, $\mathrm{Na}_{2} \mathrm{CO}_{3}$ produced by Beijing Yili Fine Chemical Co; $\mathrm{C}_{4} \mathrm{H}_{6} \mathrm{CuO}_{4} \cdot \mathrm{H}_{2} \mathrm{O}$ by Sinopharm Chemical Reagent Beijing $\mathrm{Co}$. All of the chemicals and reagents used were analytical grade and were used without further purification.

\subsection{Equipments}

Equipments included an AR2140 electronic balance provided by Ohaus Co. (Shanghai, People's Republic of China), a 81-2 isothermal magnetic agitator provided by Cile Instruments (Shanghai, People's Republic of China), a 80-2 centrifugal precipitator provided by Xinkang Yiliaoqiye Co.(Kangyan, Jiangsu Province, People's Republic of China), a DZF-6020 vacuum drying oven provided by Shanghai Bluepard instrument Co.(Shanghai, People's Republic of China), a stopwatch provided by Jun SD (Shenzhen, Guangdong Province People's Republic of China).

\subsection{Experimentalscheme}

\subsubsection{Precipitation process}

Some different kinds of copper salts $\left(\mathrm{CuCl}_{2}, \mathrm{CuSO}_{4}\right.$, $(\mathrm{CH} 3 \mathrm{COO})_{2} \mathrm{Cu}$ and $\left.\mathrm{Cu}\left(\mathrm{NO}_{3}\right)_{2}\right)$ were put in the solvent and heated to a certain temperature, then some $\mathrm{NaCO}_{3}$ 
solution was added under magnetic stirring condition for a period of time.

\subsubsection{Filtration, washing, dying and roasting}

Put mixture into centrifuge tubes and centrifuged for a period of time, then washed the precipitate using ethanol twice and put it into vacuum drying oven for $3 \mathrm{~h}$ at $50{ }^{\circ} \mathrm{C}$ to get $\mathrm{Cu}_{2}(\mathrm{OH})_{2} \mathrm{CO}_{3}$ precursor. Heated $\mathrm{Cu}_{2}(\mathrm{OH})_{2} \mathrm{CO}_{3}$ to $400^{\circ} \mathrm{C}$ for $2 \mathrm{~h}$ with heating rate $2^{\circ} \mathrm{C} \cdot \mathrm{min}^{-1}$.

\subsection{Characterization}

X-ray diffraction (XRD), fourier transform infrared (FTIR), thermogravimetric analysis (TG), scanning electron microscopy (SEM) and particle surface area measurements were used to analyse chemical composition, structure and properties of the nano- $\mathrm{CuO}$ generated.

\section{Results and discussions}

\subsection{Factors influence the experimental process}

The volume of $\mathrm{CH}_{3} \mathrm{CH}_{2} \mathrm{OH}$ was studied in single factor experiment and then the orthogonal test method was adopted to explore the influences of 4 factors on the products in order to study the factors that influenced nano- $\mathrm{CuO}$. Influence of single factor was given in table 1 and orthogonal factors were given in table 2 .

Table 1. Experimental design with single factor

\begin{tabular}{ccccc}
\hline sequence & reactants & temperature & $\begin{array}{c}\text { solvent } \\
\left(\mathrm{CH}_{3} \mathrm{CH}_{2} \mathrm{OH}: \mathrm{H}_{2} \mathrm{O}\right)\end{array}$ & time \\
\hline I & $\mathrm{CuCl}_{2}$ & $20^{\circ} \mathrm{C}$ & pure water & $15 \mathrm{~min}$ \\
II & $\mathrm{CuCl}_{2}$ & $20^{\circ} \mathrm{C}$ & $1: 1$ & $15 \mathrm{~min}$ \\
III & $\mathrm{CuCl}_{2}$ & $20^{\circ} \mathrm{C}$ & $1: 2$ & $15 \mathrm{~min}$ \\
IV & $\mathrm{CuCl}_{2}$ & $20^{\circ} \mathrm{C}$ & $1: 3$ & $15 \mathrm{~min}$ \\
\hline
\end{tabular}

Table 2. Experimental design of orthogonal experiment

\begin{tabular}{|c|c|c|c|c|}
\hline sequence & reactants & $\begin{array}{c}\text { solvent } \\
\left(\mathrm{CH}_{3} \mathrm{CH}_{2} \mathrm{OH}: \mathrm{H}_{2} \mathrm{O}\right)\end{array}$ & temperature & time \\
\hline 1 & (1) $\left(\mathrm{CH}_{3} \mathrm{COO}\right)_{2} \mathrm{Cu}$ & (1)pure water & (1) $20^{\circ} \mathrm{C}$ & (1) $15 \mathrm{~min}$ \\
\hline 2 & (1) $\left(\mathrm{CH}_{3} \mathrm{COO}\right)_{2} \mathrm{Cu}$ & (2) $1: 1$ & (2) $40^{\circ} \mathrm{C}$ & (2) $30 \mathrm{~min}$ \\
\hline 3 & (1) $\left(\mathrm{CH}_{3} \mathrm{COO}\right)_{2} \mathrm{Cu}$ & (3) $1: 2$ & (3) $60^{\circ} \mathrm{C}$ & (3) $45 \mathrm{~min}$ \\
\hline 4 & (1) $\left(\mathrm{CH}_{3} \mathrm{COO}\right)_{2} \mathrm{Cu}$ & (4) $1: 3$ & (4) $80^{\circ} \mathrm{C}$ & (4) $60 \mathrm{~min}$ \\
\hline 5 & (2) $\mathrm{CuCl}_{2}$ & (1) pure water & (2) $40^{\circ} \mathrm{C}$ & (3) $45 \mathrm{~min}$ \\
\hline 6 & (2) $\mathrm{CuCl}_{2}$ & (2) $1: 1$ & (1) $20^{\circ} \mathrm{C}$ & (4) $60 \mathrm{~min}$ \\
\hline 7 & (2) $\mathrm{CuCl}_{2}$ & (3) $1: 2$ & (4) $80^{\circ} \mathrm{C}$ & (1) $15 \mathrm{~min}$ \\
\hline 8 & (2) $\mathrm{CuCl}_{2}$ & (4) $1: 3$ & (3) $60^{\circ} \mathrm{C}$ & (2) $30 \mathrm{~min}$ \\
\hline 9 & (3) $\mathrm{CuSO}_{4}$ & (1) pure water & (3) $60^{\circ} \mathrm{C}$ & (4) $60 \mathrm{~min}$ \\
\hline 10 & (3) $\mathrm{CuSO}_{4}$ & (2) $1: 1$ & (4) $80^{\circ} \mathrm{C}$ & (3) $45 \mathrm{~min}$ \\
\hline 11 & (3) $\mathrm{CuSO}_{4}$ & (3) $1: 2$ & (1) $20^{\circ} \mathrm{C}$ & (2) $30 \mathrm{~min}$ \\
\hline 12 & (3) $\mathrm{CuSO}_{4}$ & (4) $1: 3$ & (2) $40^{\circ} \mathrm{C}$ & (1) $15 \mathrm{~min}$ \\
\hline 13 & (4) $\mathrm{Cu}\left(\mathrm{NO}_{3}\right)_{2}$ & (1) pure water & (4) $80^{\circ} \mathrm{C}$ & (2) $30 \mathrm{~min}$ \\
\hline 14 & (4) $\mathrm{Cu}\left(\mathrm{NO}_{3}\right)_{2}$ & (2) $1: 1$ & (3) $60^{\circ} \mathrm{C}$ & (1) $15 \mathrm{~min}$ \\
\hline 15 & (4) $\mathrm{Cu}\left(\mathrm{NO}_{3}\right)_{2}$ & (3) $1: 2$ & (2) $40^{\circ} \mathrm{C}$ & (4) $60 \mathrm{~min}$ \\
\hline 16 & (4) $\mathrm{Cu}\left(\mathrm{NO}_{3}\right)_{2}$ & (4) $1: 3$ & (1) $20^{\circ} \mathrm{C}$ & (3) $45 \mathrm{~min}$ \\
\hline
\end{tabular}

In experiment above, the concentration of $\mathrm{Cu}^{2+}$ is operation voltage of $30 \mathrm{kV}$. Figure 1 was SEM $0.1 \mathrm{~mol} / \mathrm{L}$, the volume of dispersant that contained $\mathrm{CH}_{3} \mathrm{CH}_{2} \mathrm{OH}$ and $\mathrm{H}_{2} \mathrm{O}$ is $40 \mathrm{~mL}$. The concentration of precipitant $\left(\mathrm{Na}_{2} \mathrm{CO}_{3}\right)$ is $0.1 \mathrm{~mol} / \mathrm{L}$ and the solvent is 40 $\mathrm{mL}$.

\subsection{SEM analysis of Nano-CuO}

Tested nano-CuO above using Hitachi S-4700 under micrographs of nano- $\mathrm{CuO}$ under different conditions with one factor changing. ( $a, b$ were the micrographs under condition I; c, d were the micrographs under condition II; $\mathrm{e}$, f were the micrographs under condition III; g, h were the micrographs under condition IV). Figure 2 and 3 were SEM micrographs of nano-CuO of orthogonal experiment ( micrograph A to $\mathrm{P}$ was sequence 1 to 16 respectively ). 


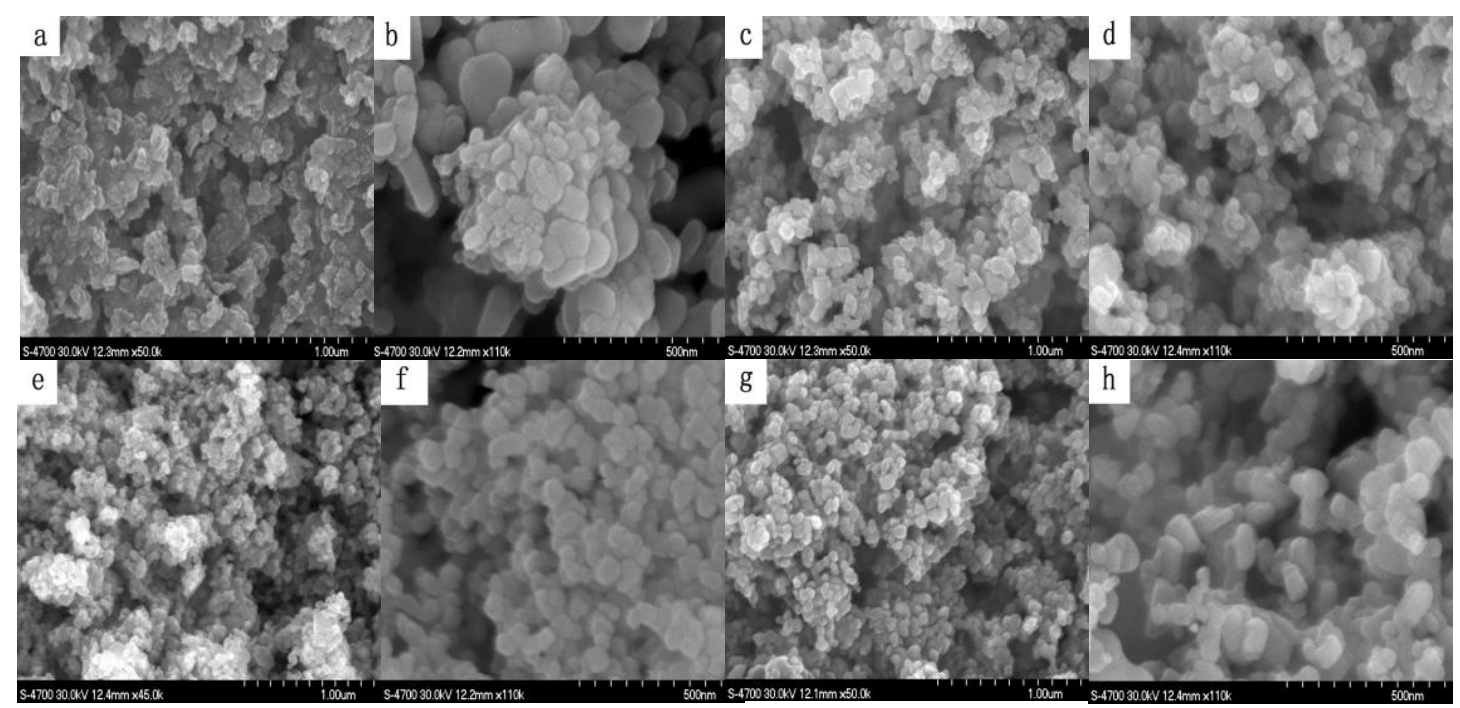

Figure 1. SEM micrographs of Nano-CuO under different conditions (I , II, III and IV)

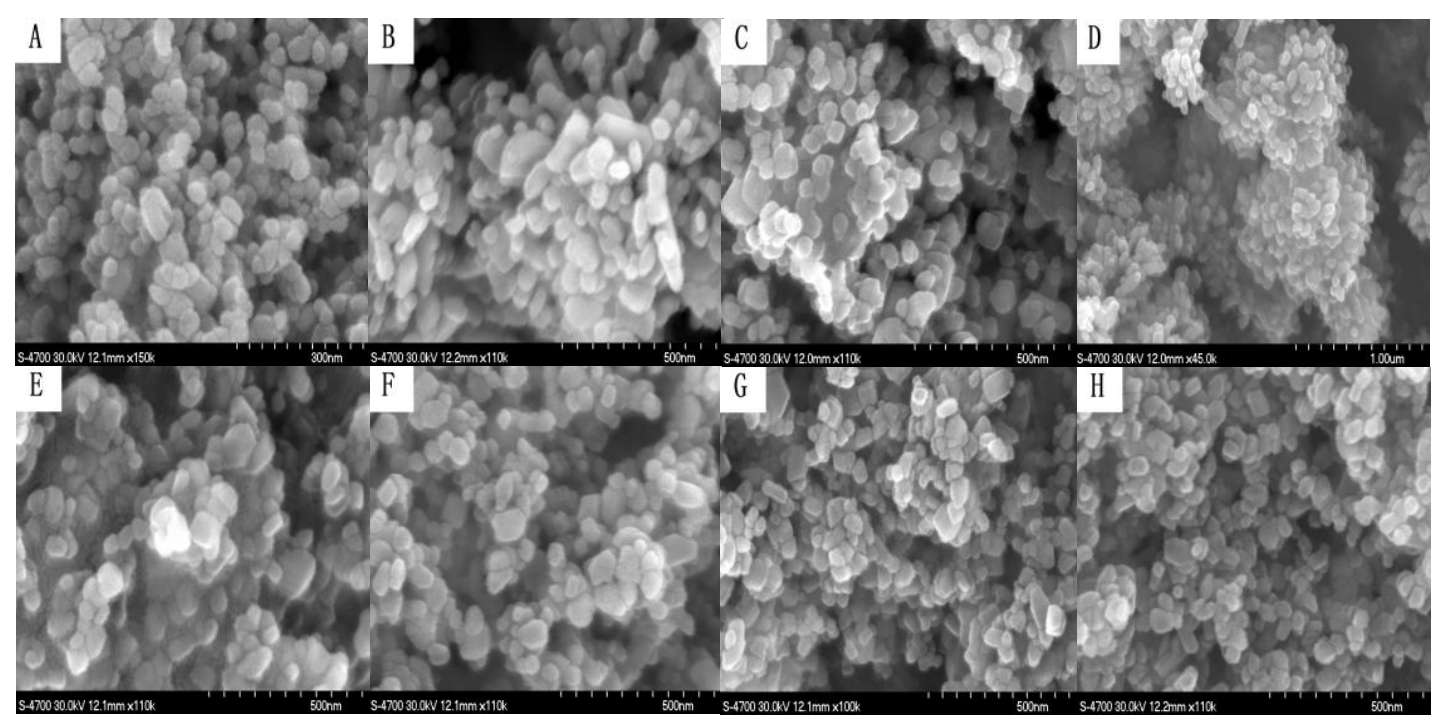

Figure 2. SEM micrographs of Nano-CuO under different conditions (1 to 8)

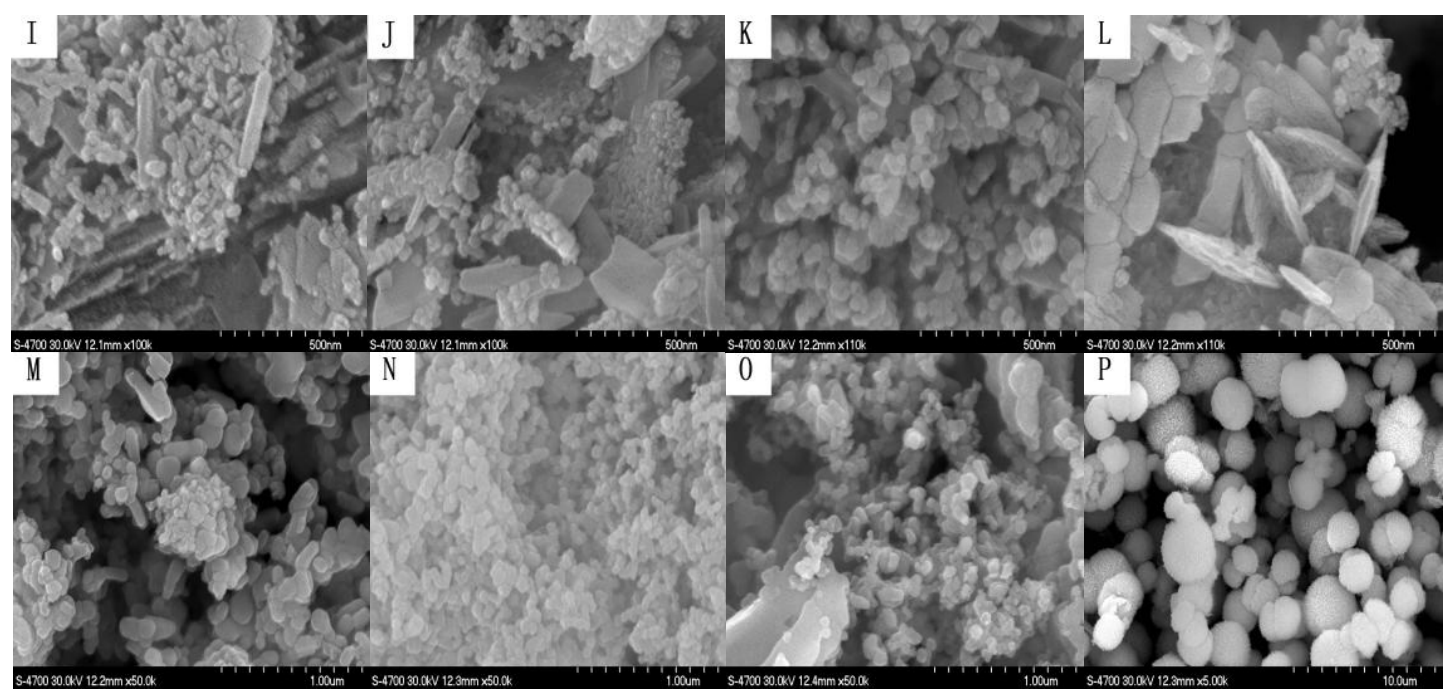

Figure 3. SEM micrographs of Nano-CuO under different conditions (9 to 16) 
From the micrographs above, figure $\mathrm{A}$ and $\mathrm{P}$ that correspond to condition 1 and 16 were best among the figures because the nano- $\mathrm{CuO}$ had good dispersion and uniform size. The dispersion of nano- $\mathrm{CuO}$ became better when proportion of $\mathrm{CH}_{3} \mathrm{CH}_{2} \mathrm{OH}$ increased. Reaction temperature and reaction time had effect on the reactants' morphology and size, and the nano- $\mathrm{CuO}$ generated by $\mathrm{CuCl}_{2}$ was best. Figure 4 was the micrographs under condition 1 and 16 with different magnifications.

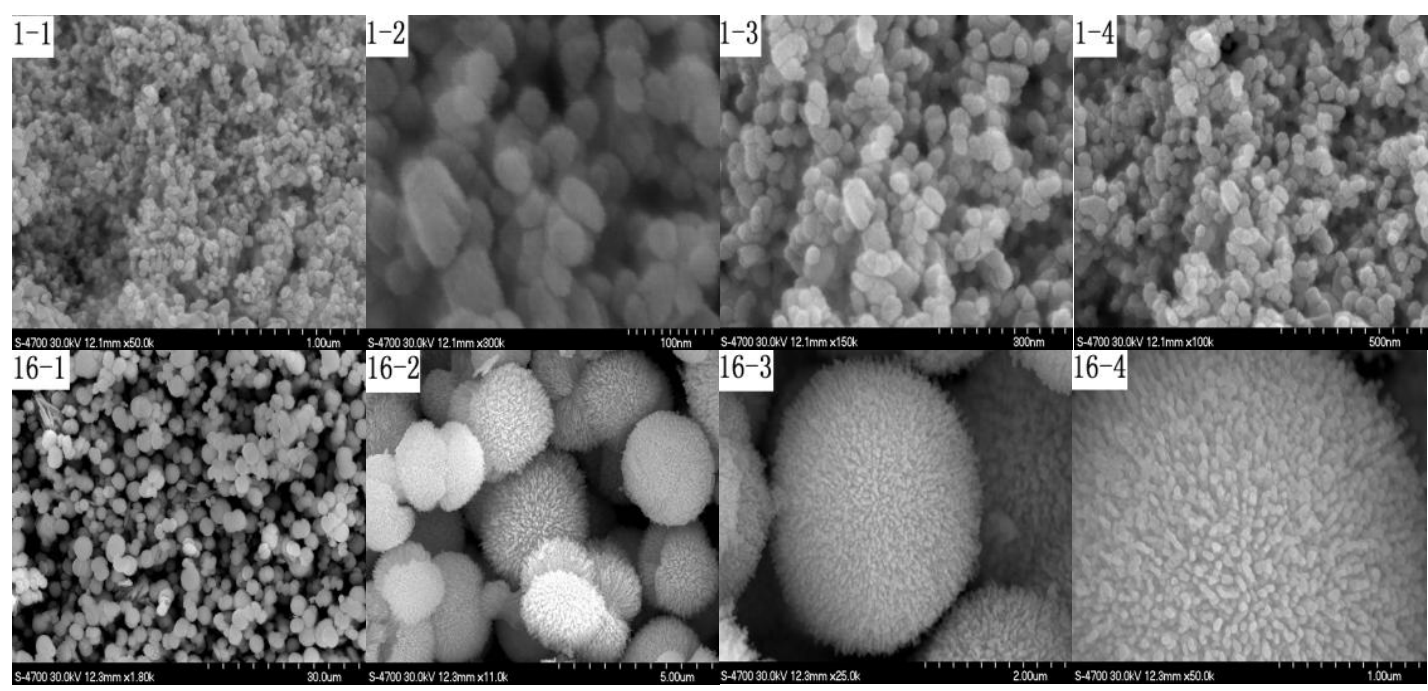

Figure 4. SEM micrographs of nano-CuO with different magnifications under condition 1 and 16

From figure 4, the nano- $\mathrm{CuO}$ generated under condition 16 was better than that under condition 1 .

\subsection{FTIR analysis of nano-CuO}

Tested the nano-CuO prepared under condition 16 using FTIR using TENSOR 27. Figure 5 gave the results of final resultant and the precursor.

From figure 5, peaks around $536 \mathrm{~cm}^{-1}$ for strong bands of the $\mathrm{Cu}-\mathrm{O}$ stretching vibrations and $582 \mathrm{~cm}^{-1}$ for strong bands of the lattice vibration were observed, and peaks of the O-C-O stretching vibrations were found at $1379 \mathrm{~cm}^{-1}$ and $1481 \mathrm{~cm}^{-1}$. Peaks at $839 \mathrm{~cm}^{-1}$ and $754 \mathrm{~cm}^{-1}$ for the $\mathrm{O}-\mathrm{H}$ stretching vibrations were observed as well, and in addition, peak of $\mathrm{Cu}-\mathrm{OH}$ around $487 \mathrm{~cm}^{-1}$ was noticed. This observation provides evidence that the final resultant and the precursor were $\mathrm{CuO}$ and $\mathrm{Cu}_{2}(\mathrm{OH})_{2} \mathrm{CO}_{3}$ respectively.

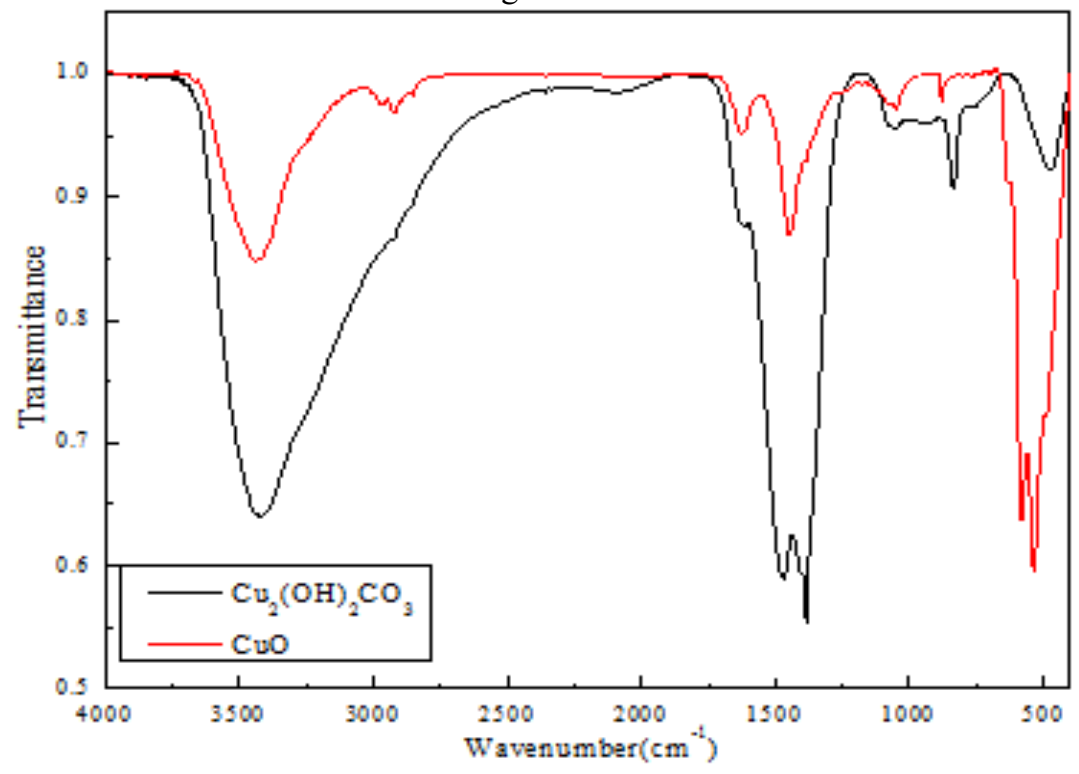

Figure 5. FTIR spectra of $\mathrm{Cu}_{2}(\mathrm{OH})_{2} \mathrm{CO}_{3}$ and $\mathrm{CuO}$ under condition 16

\subsection{TG and DTG of nano-CuO}

Tested nano-CuO above using Seiko TG/DTA 6300 with temperature varying from $30{ }^{\circ} \mathrm{C}$ to $480{ }^{\circ} \mathrm{C}$ and the heating rate was $5{ }^{\circ} \mathrm{C} / \mathrm{min}$. Figure 6 gave $\mathrm{TG}$ and $\mathrm{DTG}$ of $\mathrm{Cu}_{2}(\mathrm{OH})_{2} \mathrm{CO}_{3}$ under condition 16 .

From figure $6, \mathrm{Cu}_{2}(\mathrm{OH})_{2} \mathrm{CO}_{3}$ began to decompose 
rapidly at about $145^{\circ} \mathrm{C}$ and the strongest peak of DTG appeared at $327{ }^{\circ} \mathrm{C}$, which meant the fastest decomposition temperature was $327{ }^{\circ} \mathrm{C}$. The mass of $\mathrm{Cu}_{2}(\mathrm{OH})_{2} \mathrm{CO}_{3}$ decreased from $30{ }^{\circ} \mathrm{C}$ to $250{ }^{\circ} \mathrm{C}$ for free water's losing and $\mathrm{Cu}(\mathrm{OH})_{2}$ 's decomposing, and the decomposing of $\mathrm{CuCO}_{3}$ resulted in the rapid decreasing from $250{ }^{\circ} \mathrm{C}$ to $340{ }^{\circ} \mathrm{C}$.

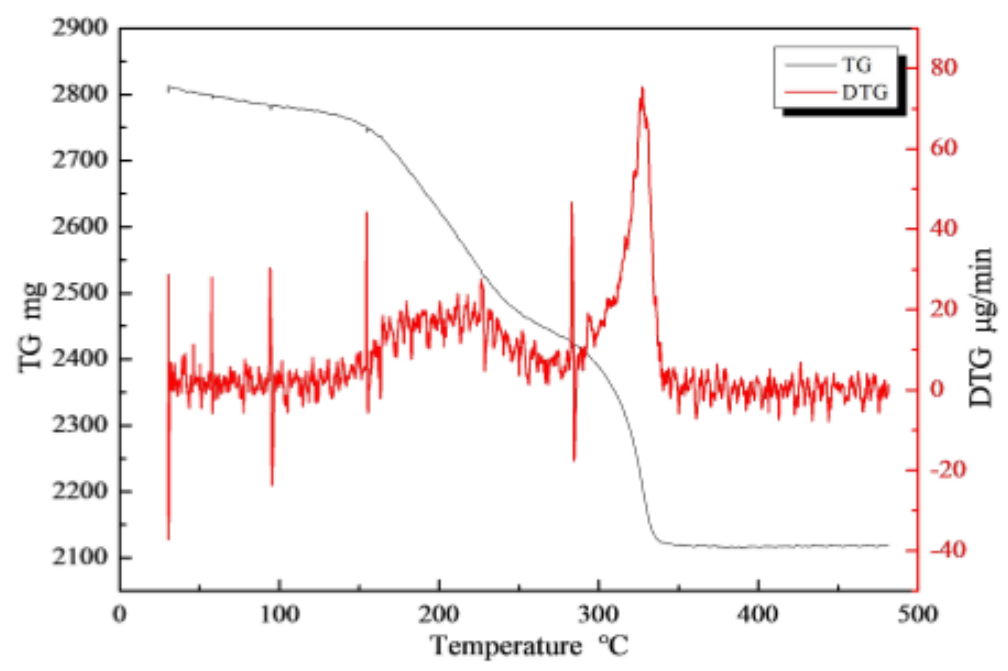

Figure 6. TG and DTG of $\mathrm{Cu}_{2}(\mathrm{OH})_{2} \mathrm{CO}_{3}$ under condition 16 .

\subsection{XRD analysis}

$\mathrm{CuO}$ generated under condition 1 and 16 and its precursor were analysed using XRD (laser power $40 \mathrm{kV} \times 40 \mathrm{~mA}$ ). From figure 7 and 8 , characteristic diffraction peaks appeared where $2 \theta$ is $14.701^{\circ}, 17.507^{\circ}, 24.084^{\circ}, 31.266^{\circ}$ and $35.557^{\circ}$, and compared with JCPDS card, the

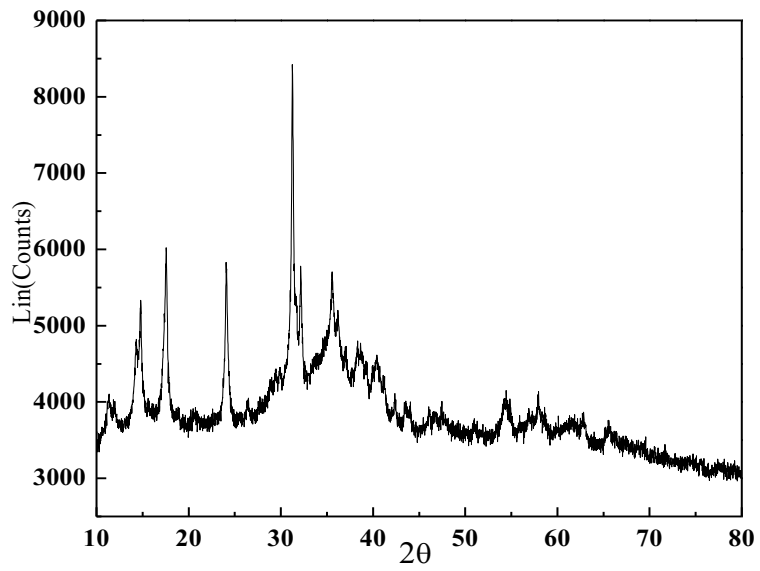

Figure 7. XRD spectrum of precursor under condition 1

From figure 9 and 10, characteristic diffraction peaks appeared where $2 \theta=32.65^{\circ}, 35.47^{\circ}, 38.86^{\circ}, 48.99^{\circ}$, $53.57^{\circ}, 58.37^{\circ}, 61.70^{\circ}, 66.43^{\circ}, 68.13^{\circ}$, and compared with JCPDS card, the material was $\mathrm{CuO}$, and material was $\mathrm{Cu}_{2}(\mathrm{OH})_{2} \mathrm{CO}_{3}$. The strongest peak appeared at $2 \theta=31.266^{\circ}, \mathrm{d}=2.85849 \mathrm{~nm}$ and the material corresponded to $\mathrm{Cu}_{2}(\mathrm{OH})_{2} \mathrm{CO}_{3}$ crystal plane (020), (021), (022), (-102), (042), (125), (123) and (135), which meant the $\mathrm{Cu}_{2}(\mathrm{OH})_{2} \mathrm{CO}_{3}$ has crystallized completely and its component was single.

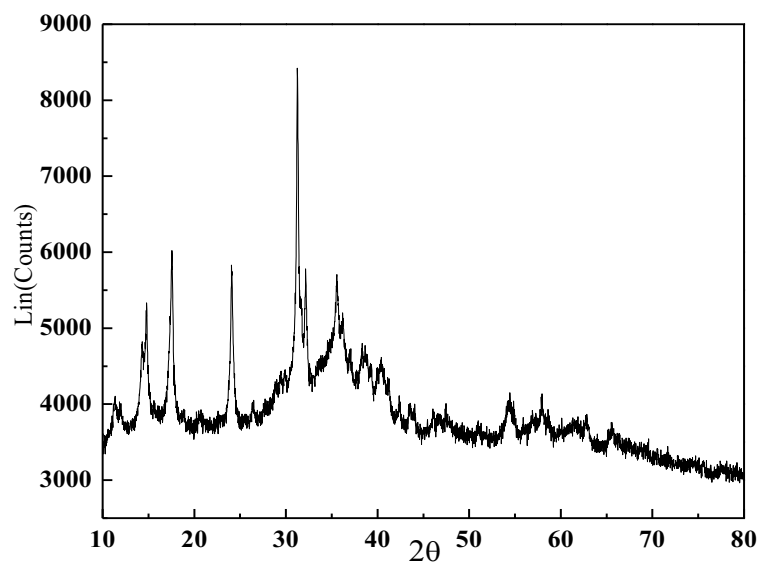

Figure 8. XRD spectrum of nano-CuO under condition 1

the strongest peak appears at $2 \theta=35.471^{\circ}, \mathrm{d}=2.52872$ $\mathrm{nm}$ and the material corresponded to $\mathrm{CuO}$ crystal plane (110), (-111), (111), (-202), (020), (202), (113), (-311) and (220). 


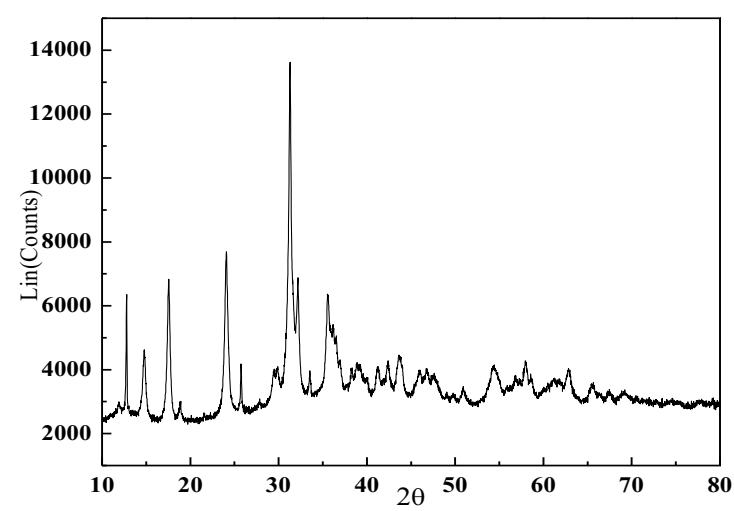

Figure 9. XRD spectrum of precursor under conditior

Calculated particle size of $\mathrm{CuO}$ and $\mathrm{Cu}_{2}(\mathrm{OH})_{2} \mathrm{CO}_{3}$ using Deby-Xeror formula as follows:

$$
\mathrm{D}_{\mathrm{C}}=\mathrm{K} \lambda /(\beta \cos \theta)
$$

Where $D_{C}$ is the size of crystal $(\mathrm{nm}), \mathrm{K}$ is the Xeror constant (to cube particles $\mathrm{K}=0.94$, to spherical particles $\mathrm{K}=0.89$ ), $\lambda$ is the wavelength of $\mathrm{X}$-ray (using $\mathrm{CuKa}$

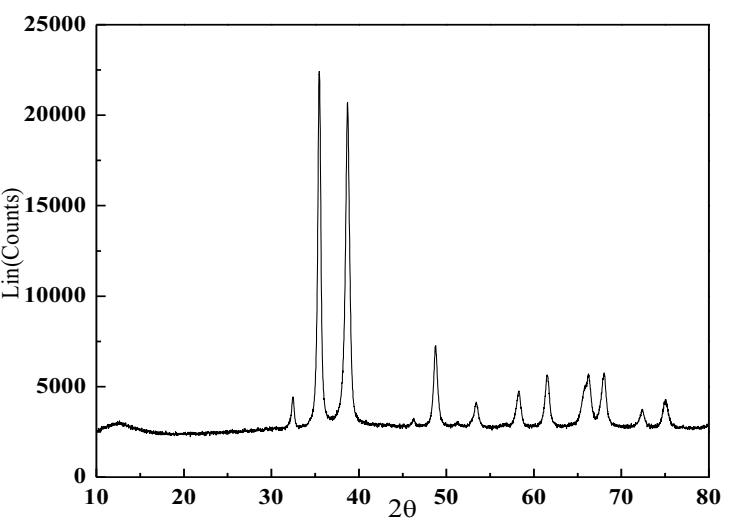

Figure 10. XRD spectrum of nano-CuO under condition 16

radiation, $\lambda=1.5406 \mathrm{~A} \approx 0.154 \mathrm{~nm}), \beta$ is full width at half maximum, $\theta$ is the diffraction angle of the peak. Particle size of $\mathrm{CuO}$ and $\mathrm{Cu}_{2}(\mathrm{OH})_{2} \mathrm{CO}_{3}$ under condition 1 and 16 were given in table 3 .

Table 3. Particle size of $\mathrm{CuO}$ and $\mathrm{Cu}_{2}(\mathrm{OH})_{2} \mathrm{CO}_{3}$ under condition 1 and 16

\begin{tabular}{llll}
\hline $\mathrm{Cu}_{2}(\mathrm{OH})_{2} \mathrm{CO}_{3}$ & Size $(\mathrm{nm})$ & $\mathrm{CuO}$ & Size $(\mathrm{nm})$ \\
\hline 1 & 27.58 & 1 & 16.20 \\
16 & 85.40 & 16 & 20.38 \\
\hline
\end{tabular}

From table 3, materials' diameter became smaller after calcinations and the size of $\mathrm{CuO}$ generated using $\mathrm{Cu}\left(\mathrm{NO}_{3}\right)_{2}$ changes more significantly than that of other materials after calcinations.
$\mathrm{CuO}$ generated under condition 16 was analysed using NOVA 4200 to get its surface area, average pore diameter and total pore volume. The nitrogen adsorption-desorption curve of nano- $\mathrm{CuO}$ under condition 16 was given in figure 11.

\subsection{Particle surface area measurements}

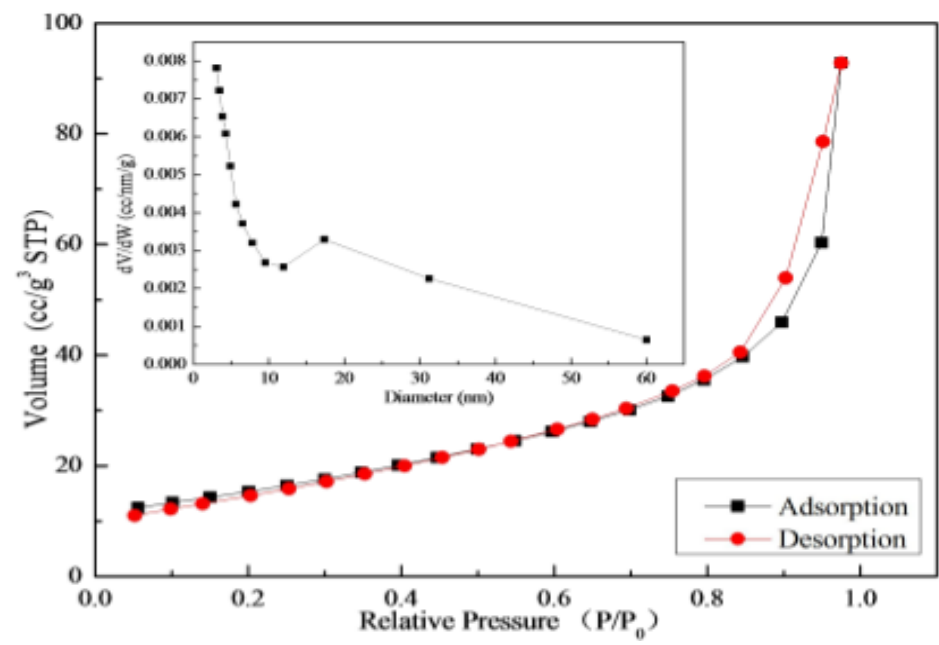

Figure 11. Nitrogen adsorption-desorption curve of nano- $\mathrm{CuO}$ under condition 16

After dealing with some procedures, the pore diameter was got, which was about $3.079 \mathrm{~nm}$ using BJH method. The surface area is $21.988 \mathrm{~m}^{2} / \mathrm{g}$ using multipoint BET method and the pore volume was $1.349 \times 10^{-1} \mathrm{cc} / \mathrm{g}$ using BJH method.

\section{Conclusions}


1 Direct precipitation method of nano- $\mathrm{CuO}$ using $\mathrm{Cu}\left(\mathrm{NO}_{3}\right)_{2}$ and $\mathrm{Na}_{2} \mathrm{CO}_{3}$ is feasible way to industry that is low cost and easy to achieve.

2 After orthogonal test, single factor experiment and characterization, best process conditions are got: reactant is $\mathrm{Cu}\left(\mathrm{NO}_{3}\right)_{2}$, temperature is $20^{\circ} \mathrm{C}$, precipitant's $\left(\mathrm{Na}_{2} \mathrm{CO}_{3}\right)$ concentration is $0.1 \mathrm{~mol} / \mathrm{L}, \mathrm{H}_{2} \mathrm{O}-\mathrm{CH}_{3} \mathrm{CH}_{2} \mathrm{OH}$ ratio is $3: 1$, reaction time is $45 \mathrm{~min}$, roasting time is $2 \mathrm{~h}$ and temperature is $400^{\circ} \mathrm{C}$.

3 Nano-CuO generated using best condition above is spherical, uniform and with good dispersivity, the average diameter of nano- $\mathrm{CuO}$ is $20.38 \mathrm{~nm}$, the surface area is about $21.988 \mathrm{~m} / \mathrm{g}$, the pore diameter was about $3.079 \mathrm{~nm}$ and the pore volume was $1.349 \times 10^{-1} \mathrm{cc} / \mathrm{g}$.

\section{Acknowledgements}

The financial support of the project supported by a foundation item from the General Armament Department of PLA (9140A0507111BQ0107), the Project of State Key Laboratory of Explosion Science and Technology, P. R. China (YBKT12-03) and the Specialized Research Fund for the Doctoral Program of Higher Education (20131101110009).

\section{References}

1. Liu Jiping, Inorganic Nano-Materials (Beijing: Science Press, 2003)

2. Li Xiaojie, $\mathrm{Qu}$ Yandong, Yan Honghao, Rare Metal Mat. Eng., 36(12), 2069(2007)

3. Chu Huaqin, Lu Yunfeng, Chinese J. Anal. Chem., 38(3), 442(2010)

4. R. V. Kumar, Y. Diamant, A. Gedanken, Chem. Mater., 8, 2301(2000)

5. Hong Weiliang, Liu Jianhong, Chen Pei, J. Propul. Techno., 22(3), 254(2001)

6. A. Bhaumik, A. M. Shearin, R. Patel, K. Ghosh, Phys. Chem. Chem. Phys., 22(16), 11054(2014)

7. Zhu Chuanfeng, Wang Jun, Micronanoelectronic Techno., 44(6), 273(2007)

8. Ye Zhao, Zhang Hanhui, Spectrosc. Spect. Anal., 23(3), 487(2003)

9. Wu Xiuwen, Jiang Xin, Chem. Equipment Techno., 25(4), 46(2004)

10. Yan Bo, Wang Xin, Shao Chunhong, Chinese J. Inorg. Chem., 23(11), 1869(2007)

11. Luo Yuanxiang, Li Dan, Yang Juan, Chinese J. Explos. Propell, 25(3), 53(2002)

12. Liu Kehui, Yan Liushui, Luo Guoan, Chinese J. Anal. Chem., 33(6), 847(2005) 